\title{
Using data assimilation to study extratropical Northern Hemisphere climate over the last millennium
}

\author{
M. Widmann ${ }^{1,2}$, H. Goosse ${ }^{3}$, G. van der Schrier ${ }^{4}$, R. Schnur ${ }^{5}$, and J. Barkmeijer ${ }^{6}$ \\ ${ }^{1}$ Institute for Coastal Research, GKSS Research Centre, Geesthacht, Germany \\ ${ }^{2}$ School of Geography, Earth and Environmental Science, University of Birmingham, UK \\ ${ }^{3}$ Institut d'Astronomie et de Géophysique George Lemâitre, Université catholique de Louvain, Belgium \\ ${ }^{4}$ Royal Netherlands Meteorological Institute (KNMI), De Bilt, The Netherlands \\ ${ }^{5}$ O.A.SYS - Ocean Atmosphere Systems GmbH, Hamburg, Germany \\ ${ }^{6}$ Royal Netherlands Meteorological Institute (KNMI), De Bilt, The Netherlands
}

Received: 10 June 2009 - Published in Clim. Past Discuss.: 7 September 2009

Revised: 31 March 2010 - Accepted: 17 May 2010 - Published: 30 September 2010

\begin{abstract}
Climate proxy data provide noisy, and spatially incomplete information on some aspects of past climate states, whereas palaeosimulations with climate models provide global, multi-variable states, which may however differ from the true states due to unpredictable internal variability not related to climate forcings, as well as due to model deficiencies. Using data assimilation for combining the empirical information from proxy data with the physical understanding of the climate system represented by the equations in a climate model is in principle a promising way to obtain better estimates for the climate of the past.

Data assimilation has been used for a long time in weather forecasting and atmospheric analyses to control the states in atmospheric General Circulation Models such that they are in agreement with observation from surface, upper air, and satellite measurements. Here we discuss the similarities and the differences between the data assimilation problem in palaeoclimatology and in weather forecasting, and present and conceptually compare three data assimilation methods that have been developed in recent years for applications in palaeoclimatology. All three methods (selection of ensemble members, Forcing Singular Vectors, and Pattern Nudging) are illustrated by examples that are related to climate variability over the extratropical Northern Hemisphere during the last millennium. In particular it is shown that all three methods suggest that the cold period
\end{abstract}

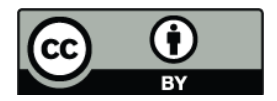

Correspondence to: $\mathrm{M}$. Widmann (m.widmann@bham.ac.uk) over Scandinavia during $1790-1820$ is linked to anomalous northerly or easterly atmospheric flow, which in turn is related to a pressure anomaly that resembles a negative state of the Northern Annular Mode.

\section{Introduction}

Estimates for past climate are usually either based on empirical evidence contained in proxy data or on simulations with climate models driven by reconstructions of climate forcing factors. A third possibility is the combination of proxy data and climate simulations using data assimilation (DA). Here we give an overview on the atmospheric DA efforts that have been undertaken to date in palaeoclimatology and of their relevance to reconstructing the climate over Scandinavia, yet we begin with a brief discussion of the links between proxy data and climate simulations without DA.

Empirical reconstructions and standard simulations yield independent results, because the proxy data used for reconstructing the forcings for the simulations are independent from those used for the empirical climate reconstructions. As the errors associated with both approaches are difficult to quantify, consistency tests between them are a key tool for assessing the confidence we can have in estimates for past climates (Jansen et al., 2007). The mismatch between the local to regional climate signals recorded in proxy data and the coarse spatial scales on which palaeoclimate simulations can be skillfull, which are on the order of thousand kilometers or more, can be overcome by using networks of proxy data to

Published by Copernicus Publications on behalf of the European Geosciences Union. 
reconstruct large-scale climate anomalies (Mann et al., 2008; Cook et al., 2002; Jones and Widmann, 2003) or full spatial fields (Mann et al., 1998; Luterbacher et al., 2002, 2004), or by using downscaling techniques to estimate regional climate from the simulations (Wagner et al., 2007).

Increasing computer power has led to a considerable number of simulations for the climate of the Holocene (Jansen et al., 2007; Wanner et al., 2008). Mainly two types of models are used for these simulations, namely Earth system Models of Intermediate Complexity (EMICs), which are based on substantially simplified atmospheric and ocean dynamics, are computationally fast and thus allow very long or ensemble simulations, and General Circulation Models (GCMs), which include a representation of climate which is as realistic as possible, but are computationally costly. In contrast to GCMs, many EMICs do not include an adequate representation of the internal climate variability on interannual to multidecadal timescales, and the main use of these models is the analysis of the long-term climate response to changes in external forcings (Claussen et al., 2002). The EMIC used here to illustrate various data assimilation methods simulates the internal climate variability reasonably well in mid and high latitudes, but strongly underestimates it in tropical regions because of the approximations applied in this model (e.g. Selten et al., 1999; Goosse et al., 2002). Both types of models are usually forced with orbital parameters, and with estimates for solar irradiance, greenhouse gas concentrations, and sometimes for volcanic aerosol concentrations. Simulations with GCMs have been performed with constant forcing factors for the Mid-Holocene (Bracconot et al., 2007), with time-dependent forcings for the last 500 years to the last millennium (von Storch et al., 2004; Tett et al., 2007) and in some cases also for most of the Holocene (Lorenz and Lohmann, 2004; Wagner et al., 2007). Due to the lower computing costs most EMIC simulations are driven with timedependent forcing factors and cover the whole Holocene (Crucifix et al., 2002; Brovkin et al., 2003; Weber et al., 2004; Renssen et al., 2005; Wang et al., 2005).

As climate variability is over a large range of timescales a combination of externally forced and of random, internally generated components, empirical reconstructions and simulations are of a different nature. Proxy-based reconstructions represent the historic climate evolution, but only for a limited set of variables, whereas climate simulations provide comprehensive representations of past climate, but usually only for a combination of the forced component and model-based internal variability. The latter is in the best case similar to the true internal variabilty in a statistical sense. The fact that the actual time evolution of random variability can not be simulated in forced simulations can in consistency tests either be taken into account through comparing ensemble simulations with empirical reconstructions, or through considering temporal averages over periods that are long enough for the climate variability to be dominated by the climate forcing.

The aim of DA in climatology is to combine dynamical models and empirical information to find estimates for past climate that are both consistent with the empirical knowledge and with the dynamical understanding of the climate system. Usually this implies representing the time evolution of random variability components in climate simulations, but other applications, which will be discussed in the next section, also exist. Moreover, DA provides estimates for variables and locations for which no empirical information exists, including large-scale atmospheric anomalies that are consistent with the local information. Using DA in palaeoclimatology has first been suggested by von Storch et al. (2000). Out of the three methods discussed later in this paper one follows directly the ideas outlined in von Storch et al. (2000), and a second one can be seen as a modification of it.

In palaeoclimatology the random variability component is likely to be of high relevance in the mid-latitudes, as these are in general characterised by a high level of natural variability. In Scandinavia natural variability is particularly high, because it is located in an area of a strong precipitation and temperature signal of the Northern Annular Mode (NAM) or the North Atlantic Ocillation (NAO), which are the dominant modes of extratropical atmospheric circulation variability in the Northern Hemisphere (Hurrell, 1995; Thompson and Wallace, 2000, 2001). The NAM/NAO variability characterises not only the mean atmospheric flow and thus the advection of air masses of different temperatures, but also the position of the Atlantic stormtrack (with the synopticscale variability potentially feeding back on the NAM/NAO state), which both are key for the climate over Northern Europe. Random decadal variability of sea surface temperature linked for instance to the Atlantic Multidecadal Oscillation (Delworth and Mann, 2000; Knight et al., 2005) or to variability in the Meridional Overturning Circulation (Hawkins and Sutton, 2008) can further strongly influence temperatures over Scandinavia (Sutton and Hodson, 2005).

The basic concepts of DA will be introduced in Sect. 2, along with a discussion of the similarities and differences between the assimilation problem in palaeoclimatology and the highly developed field of DA in meteorology and oceanography. Specific approaches developed in the context of palaeoclimatology will be presented in Sect. 3, including some results relevant to Europe, followed by a summary and conclusion section.

\section{Dynamical models and data assimilation - the standard framework}

In this section the standard framework of DA will be outlined. The purpose is not to present a comprehensive discussion, which would be far beyond the scope of this paper, but to introduce the main elements such that later it can be understood how the current status of DA in palaeoclimatology differs from this framework. 
Generally speaking dynamical models transform a state of a system at a given time $(\boldsymbol{\Psi}(t))$ into a state at a later time $(\boldsymbol{\Psi}(t+\Delta t))$. The time development may be influenced by time-dependent forcing factors (forcing $(t)$ ), and the model $F$ often contains a set of parameters that specify a certain model among a class of models. We thus can write

$\boldsymbol{\Psi}(t+\Delta t)=F_{\text {parameter }}(\boldsymbol{\Psi}(t)$, forcing $(t))$

In a standard forced simulation empirical knowledge about the system is only used in a very general (yet often sophisticated) way during model development to formulate the model itself, which includes determining the basic equations that constitute the structure of the model, and setting specific values for its parameters. The time evolution of the states follows from the forcing as well as from the initial state from which the model was started, with predictability limits due to the usually chaotic nature of the system.

The purpose of DA is to use empirical knowledge of the temporal development of the system states after the model has been constructed. In principle DA can be used in two different ways, namely to estimate the system state, or to systematically improve model parameters. In this paper we will focus on methods that are related to the first aim, and either correct simulated states or select states from ensemble simulations. Examples for the second case can be found for instance in Annan et al. (2005).

The first type of problem, which is also known as state estimation, is encountered in many scientific disciplines, and a mathematically sound framework for it exists (for an overview see for instance Swinbank et al. (2003)). The field in which DA is most closely related to the DA problem in palaeoclimatology is numerical weather prediction, where DA is used to find the best estimate for the current state of the atmosphere, which is then used to start the forecast. Information about the state of the atmosphere at a given time can be obtained in two ways, firstly from a forecast started earlier, and secondly from the observations at that time or at a later time. This key problem in weather forecasting of finding the initial state for a forecast is solved by combining a previous forecast with observations, which include direct surface and upper air meteorological measurements, as well as indirect observations of meteorological variables through satellites.

In an optimal combination of the forecast-based and the observation-based estimates for the atmospheric state, the relative weights of these two types of information depend on their errors, with more weight given to the estimates with less uncertainty. The formulation of the best estimate, which is called the analysis, also needs to take into account the fact that the observations and the simulated states usually consist of different variables, and are defined at different locations. The goal is to find a model state that is consistent with the observations and with the previous forecast. To a good approximation this also means that the sequence of analysis states is consistent with the model physics, which is not true for a sequence of states that are obtained from a statistcial interpolation of direct observations. The fact that the simulated states and the observations are fundamentally different quantities is included in the formalism by an observation operator $h$ that transforms the simulated state $\boldsymbol{\Psi}$ (all model variables at all model locations) at a given time into the observations $\boldsymbol{\Theta}$ (all observed variables at all observed locations) that would be obtained given $\Psi$. Examples include the transformation from temperature or pressure on model gridcells (often on the order of $100 \mathrm{~km} \times 100 \mathrm{~km}$ ) to local measurements, or the transformation of a vertical temperature profile to satellite microwave retrievals.

In the classical framework for state estimation it can be shown that given $N$ observations $\boldsymbol{\Theta}_{i}$ at times $t_{i}$, the optimal analysis $\boldsymbol{\Psi}_{a}$ at time $t_{0}\left(<t_{i}\right)$ is obtained by minimising the following cost function with respect to $\Psi$

$$
\begin{aligned}
\min J(\Psi)= & \frac{1}{2}\left(\boldsymbol{\Psi}-\boldsymbol{\Psi}^{b}\right)^{T} \mathbf{B}^{-1}\left(\boldsymbol{\Psi}-\boldsymbol{\Psi}^{b}\right) \\
& +\frac{1}{2} \sum_{i=1}^{N}\left(h_{i}\left(\boldsymbol{\Psi}_{i}\right)-\boldsymbol{\Theta}_{i}\right)^{T} \mathbf{R}_{i}^{-1}\left(h_{i}\left(\boldsymbol{\Psi}_{i}\right)-\boldsymbol{\Theta}_{i}\right),
\end{aligned}
$$

where $\boldsymbol{\Psi}^{b}$ is the previous forecast (also known as the background field) at time $t_{0}$, and $\boldsymbol{\Psi}_{i}$ and $h_{i}$ are the simulated field and the observation operator at times $t_{i}$. The errors in the simulation are given by the error covariance matrix $\mathbf{B}$, while the observation errors are described by the error covariance matrix $\mathbf{R}$.

In the special case of sequential data assimilation, in which the observations are assimilated one at a time (i.e. $N=1$ in Eq. 2) the solution can be approximated by

$$
\boldsymbol{\Psi}^{a}=\boldsymbol{\Psi}^{b}+\mathbf{G}\left(\mathbf{H}\left(\boldsymbol{\Psi}^{b}\right)-\boldsymbol{\Theta}\right)
$$

where $\mathbf{H}$ is the linearisation of the observation operator $h$, and $\mathbf{G}$ is the so-called gain matrix. The gain matrix is calculated from the error matrices $\mathbf{B}$ and $\mathbf{R}$. For linear dynamical systems this approximation is exact.

Methods that directly minimise the cost function in Eq. (2) are called variational data assimilation (3D-VAR for $N=1$, $4 \mathrm{D}-\mathrm{VAR}$ for $N>1$ ), while sequential methods of the type of Eq. (3) are known as filters. Two examples of filters are briefly discussed in Sect. 3.2, namely the Kalman Filter and the Particle Filter. Equation (3) only uses previous information to estimate the state of the system at a past time $t$. However, in palaeoclimatology observations from this time $t$ up to the present are also generally available. Those additional constraints on the system at time $t$ can be used with so-called smoothers (e.g., Wunsch, 2006), which propagate information backward in time (whereas Eq. 3 only propagates it forward), but to the authors' knowledge such a technique has not yet been used in palaeoclimatology. Although the exact 
solution for the analysis is theoretically clear, the main problem in practical applications with variational and sequential approaches is to specify the time-dependent error matrices such that useful solutions are obtained.

\section{Data assimilation in palaeoclimatology}

\subsection{Differences between weather forecasting and palaeoproblems}

Numerical weather forecasts and palaeoclimatic simulations both use GCMs. However, assimilation methods developed for weather forecasting cannot be implemented in models used in palaeoclimatology because of fundamental differences in the extent, temporal resolution and type of empirical information about the system state. Additionally, the mechanisms that cause a climate signal in proxy data are often only incompletely understood.

Each day there are several hundred thousand in situ and remote sensing observations of the state of the atmospere and ocean available that can be assimilated to initialise weather foreasts. All of these are physical measurements, either direct or indirect, and it is thus well known how they are linked to the state of the atmosphere or ocean, in other words the observation operator $h$ is relatively well known. Decades of development of assimlation methods at the main weather forecasting centres have led to the currently used variational assimilation schemes that are optimised for this situation. The same methods have also been used in the NCEP/NCAR (National Center for Environmental Prediction/National Center for Atmospheric Research) and the ERA40 (European Reanalysis) atmospheric reanalysis projects, where constant model versions have been used to assimilate observations from the last decades (Kalnay et al., 1996; Kistler et al., 2001; Uppala et al., 2005). These reanalyses provide the most consistent and comprehensive estimates for the atmospheric states from 1948 (NCEP/NCAR) or 1958 (ERA40) to the present.

More recently DA has also been applied to use the surface meteorological observations that extend back to the beginning of the 20th century for a reanalysis (Whitaker et al., 2004; Compo et al., 2006, 2010). During the development of this "100 year reanalysis" it became clear that the variational methods used for the NCEP/NCAR and ERA40 reanalyses are not suitable for dealing with the much sparser set of observations available for the longer analysis, whereas an Ensemble Kalman Filter methdod performed well under these circumstances.

The situation in palaeoclimatology is different in many respects. Even for the last millennium the number of climate proxy data is a few orders of magnitude lower than in the early 20th century. In addition, the type of data is fundamentally different as it typically includes seasonal or annual climate signals rather than instantaneous information.
Changing the implementations of the variational techniques such that they take into account the fact that the observations represent temporal means is a theoretical and technical challenge that has not yet been addressed. In the case of using proxy data the observation operator would describe how climate states are transformed into the climate signals contained in proxy data, which in this context is also known as forward modelling. Forward modelling of proxy data is a developing field (Reichert et al., 1999, 2001; Weber and Oerlemans, 2003; Evans et al., 2006), but for most proxy data the observation operator would not be readily available. An intermediate solution, which is used in the methods discussed in the following sections, is to infer regional or large-scale climate states from the proxy data through transfer functions (regional) or upscaling methods (large-scale). It should however be noted that these approaches are potentially problematic because the (unknown) forward models may be non-invertible and because many methods have a tendency to underestimate variability (e.g. Christiansen et al., 2009). The final key ingredient for the standard DA approach outlined above are realistic estimates for the model and the observation errors, which usually also do not exist in paleoclimatology.

Because of these multiple challenges and because DA for palaeoclimatology is an emerging field which has not been worked on by the major modelling centres, the methods used are only loosely linked to the methods used in the mature field of weather forecasting and atmospheric reanalyses. The approaches taken are fairly pragmatic and are discussed in the following two sections.

\subsection{Ensemble member selection}

The goal of ensemble techniques is to approximate the statistical behavior of the system from a finite number of $N$ randomly generated states. In practice these $N$ states are obtained by performing an ensemble of $N$ simulations with a model, varying initial conditions, model parameters and forcing, in a reasonable range. The update of this reasonable range as time goes by is generally a key element of the method. Ensemble techniques appear well adapted for DA in paleoclimatology as it is possible to perform DA even in the presence of strong non-linearities (e.g., Evensen, 1997; Pitt and Shepard, 1999; Cappe et al., 2007). Furthermore, ensemble techniques are relatively easy to implement, as they generally do not require strong modifications in the code of the climate model nor strong development (as the methods presented in Sects. 3.3.1 and 3.3.2).

Mainly two groups of ensemble methods have been used up to now in paleoclimatology: Ensemble Kalman filters (EnKF) and particle filters. EnKF can easily be described in the classical framework described in Sect. 2 (Evensen, 1997; Burgers et al., 1998; Evensen, 2003). Both the background state and the gain matrix are computed from statistics of the ensemble, obtaining then the analysis and estimate of the 
uncertainty as in many sequential methods. These ensemble statistics are also used to generate the new ensemble for the next analysis step. In particle filters, the gain matrix is not necessarily computed explicitly. Instead, a time-dependent weight is computed for each member of the ensemble from its ability to reproduce the observations used to constrain the model. Resampling of the ensemble is often necessary to cover well the domain of variation of the system while keeping the total number of particles reasonable. From the ensemble of simulations and the weights, it is easy to compute the (weighted) mean and the dispersion of the ensemble, providing an estimate of the state of the system and of the uncertainty on this estimate (e.g., Pitt and Shepard, 1999; Liu and West, 2001; Cappe et al., 2007).

Up to now, none of those methods has been used to perform transient simulations over the Holocene or even the last millennium. However, a technique applied recently can be interpreted as a degenerated particle filter (Collins, 2003; Goosse et al., 2006, 2009, 2010). Indeed, as in the particle filter method, at the end of each step (1 year up to 50 years), all the simulations are compared to the available observations. Nevertheless, the weights are obtained in a much simpler way than in the full particle filter algorithm: the simulation that is the closest to observations, i.e. that minimises a cost function, receives a weight of 1 while all the others have a weight of 0 . The next step is then performed using this best simulation as initial condition, adding some noise in order to sample the uncertainty of the system and generate a new ensemble.

This method has been tested over various periods of the past millennium, using instrumental as well as proxy data (e.g., Goosse et al., 2006, 2009, 2010; Crespin et al., 2009). To illustrate the method here, we will show its performance over Scandinavia from 11 simulations performed over the past 600 years using the EMIC LOVECLIM (Goosse et al., 2010). These eleven simulations differ in some model parameters, the forcing applied, as well as in some parameters of the DA technique but they are all constrained by the same set of 56 Northern Hemisphere proxy series derived from a recent compilation (Mann et al., 2008). These time series have been selected from a larger set in order to keep only those that are significantly correlated with instrumental time series over the years 1850-1995 and have been decadally smoothed. As a consequence, model results have also been decadally smoothed before plotting them. This means that the observation operator $h$ is relatively simple here. However, it would be interesting to use a more sophisticated one, in particular through the inclusion of forward models that directly simulate the proxy variable from the model results.

As imposed by the DA method, the simulations follow very well the available proxy data over Scandinavia (Fig. 1a). Although the average over the 11 simulations with data assimilation appears to underestimate multi-decadal variations, its correlation with the mean of the proxy data reaches 0.89 over the period 1400-1995. It should be noted that averaging
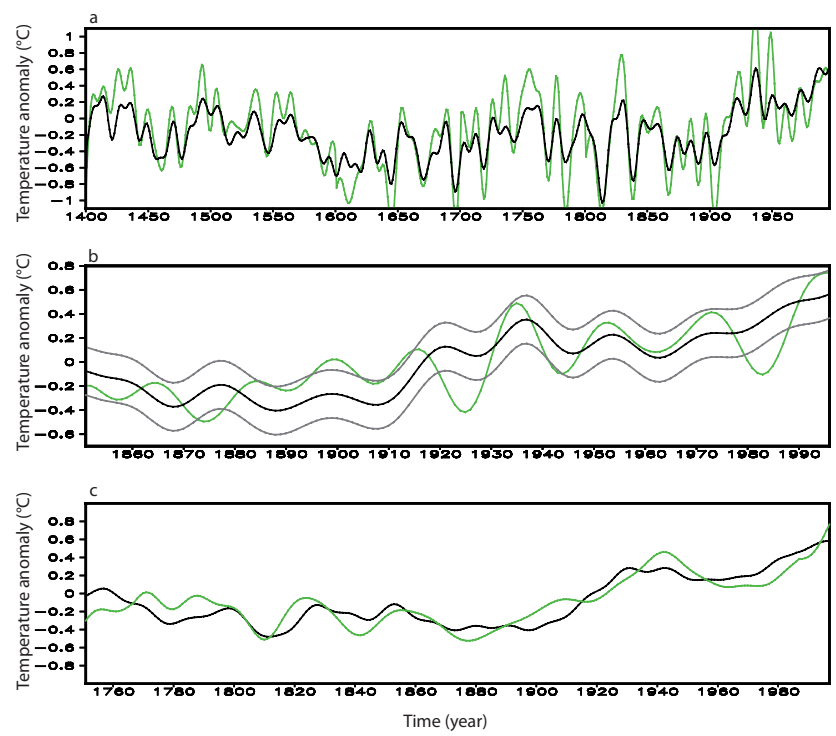

Fig. 1. Time series $\left({ }^{\circ} \mathrm{C}\right)$ of the anomaly in annual mean surface temperature averaged over the 11 simulations using DA (black) for Scandinavia (defined here as the region $5^{\circ}-35^{\circ} \mathrm{E}$, and $55-75^{\circ} \mathrm{N}$ ) and (a) the average of the 6 proxies used to constrain model results in this region (green), (b) the instrumental data compiled in the HadCRUT3 data set (green, Brohan et al., 2006), and (c) the average over Stockholm and Uppsala long instrumental time series, (Moberg et al., 2003). For (a), model results are averaged only over the points where proxy data are available. Reference period is 1850-1995. All the time series have been decadally smoothed. A 21-year running mean has been applied for panel (c).

of ensemble members from DA simulations does not necessarily lead to a reduction of multi-decadal variability. If the assimilated information fully constrained the multi-decadal variability, all ensemble members would have the same temporal development and no variability reduction would occur. If the constraints were weak, the ensemble members would differ strongly, similar to simulations without DA, which at best capture forced but not internally generated multi-decadal variability, and thus averaging would reduce variability. The average over the 11 simulations with data assimilation is also in very good agreement with instrumental observations over 1850-1995 in this region (Brohan et al., 2006), with a correlation between the two time series of 0.74 , i.e. more than all the local correlations between the proxies and the instrumental observations (Fig. 1b). Only a few instrumental data are available before 1850 . We have compared our model results with two of the longest ones (Fig. 1c), Stockholm and Uppsala, that include the second half of the 18th century and whose quality and homogeneity has been carefully checked (Moberg et al., 2003). These simulations with data assimilation are not able to reproduce well the high-frequency variations recorded at those two locations (not shown) but the long-term trend is in good agreement with model results (Fig. 1c). 

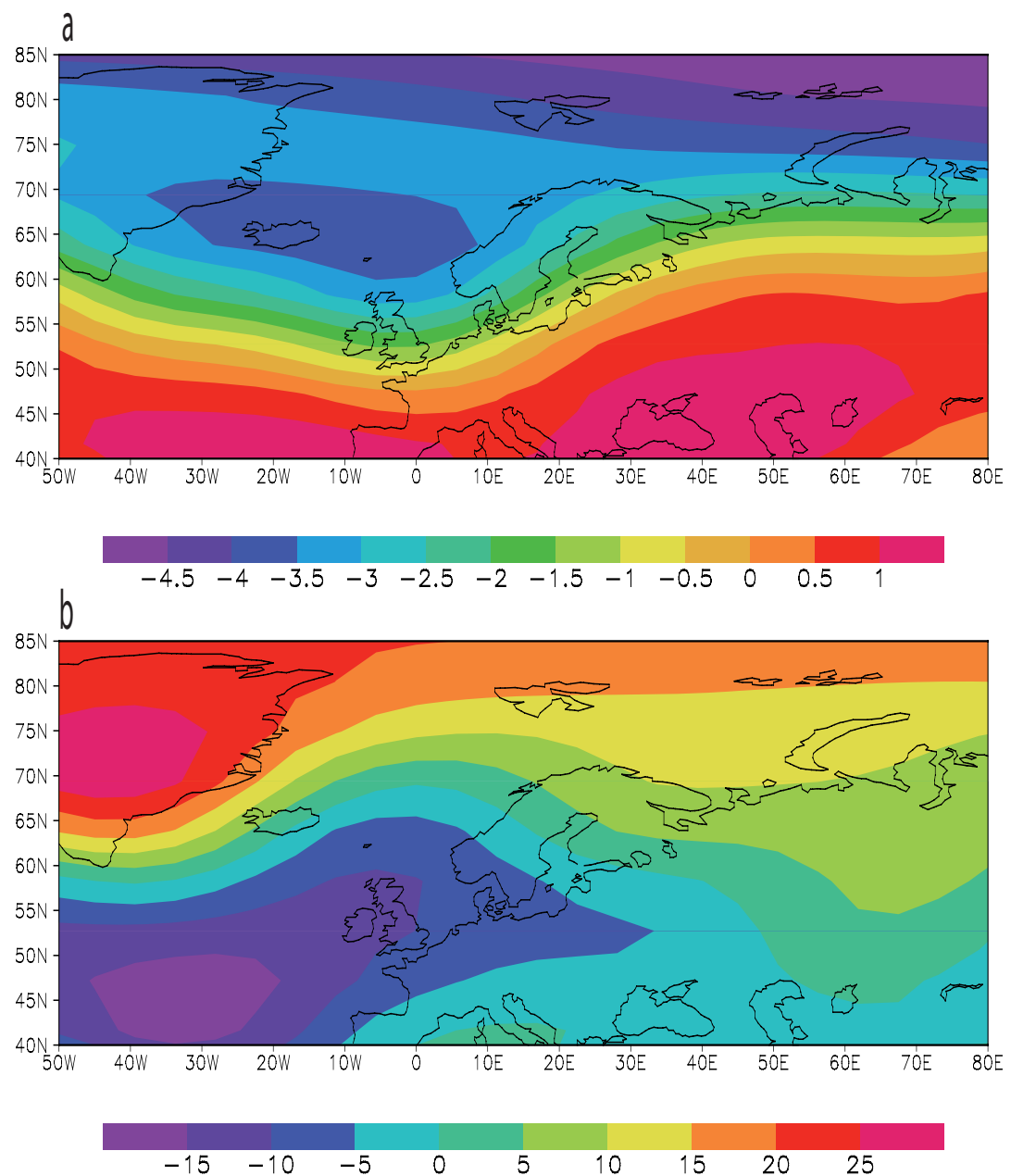

Fig. 2. (a) Difference in winter geopotential height $(m)$ averaged over the 11 simulations using data assimilation between the periods $1401-$ 1500 and 1601-1700. (b) Anomaly of winter geopotential height $(\mathrm{m})$ averaged over the 11 simulations using data assimilation in the period 1790-1820 compared to the reference period 1850-1995.

This comparison is instructive as it shows that, although the data assimilation method is simple, the data constraint is efficient. However, because of the decadal smoothing, the number of degree of freedom is relatively low, partly explaining the good correlation achieved by the ensemble member selection. Furthermore, temperature estimates for Scandinavia, derived from the proxies, are directly used to constrain model results. As a consequence, in the present framework, the temperature in Scandinavia obtained in the simulation with DA does not bring clear new information compared to the proxy data themselves (Fig. 1a). This is not always the case. Data assimilation can be considered as a sophisticated way to obtain reconstructions in areas where no proxy is available or to derive large-scale reconstructions. Those reconstructions based on simulations with DA are constrained by available proxies (as any reconstruction based on statistical methods) but, in addition, they ensure that the dynamics of the system represented by model equation is respected. Finally, in some areas where different proxies show incompatible time series, DA can be a way to select the ones that are the most compatible with model dynamics and thus most likely represent a good large-scale estimate of past climate changes.

As simulations with DA provide also estimates of variables that cannot be directly derived from the proxy records, a first step to evaluate DA simulations is to measure the quality and robustness of these estimates as they are less constrained by proxies than the variables directly assimilated. The mechanisms responsible for the changes in simulations with DA can then be analysed. For instance, when comparing the winter atmospheric circulation between the 15 th century and the 17 th century (which are relatively warm and cold periods in Scandinavia, respectively, Fig. 1a) a relatively weak but clear signal resembling a shift from a 
positive to a negative phase of the North Atlantic Oscillation emerges (Fig. 2a). When focusing on the years 17901820, as in van der Schrier and Barkmeijer (2005), a pattern resembling the negative phase of the North Atlantic Oscillation is obtained for this cold period in Europe (Fig. 2b). This circulation anomaly in the simulations with DA presents clear similarities with the reconstruction of van der Schrier and Barkmeijer (2005), in particular over Northern Europe (see Fig. 3). However, their pattern is associated with much stronger northerly wind anomalies East of Britain, in the North Atlantic, than the one displayed in Fig. 2b.

\subsection{Upscaling and control of large-scale circulation}

We now consider two methods that allow assimilation of large-scale climate anomalies without using an ensemble technique. Both methods have been applied to assimilate atmospheric circulation patterns but in principle they could also be used to assimilate temperature. We note that largescale anomalies could also be assimilated with ensemble techniques, but these would be computationally very costly when applied to GCMs.

Focusing on circulation is motivated by two reasons. Firstly, simulated continental-scale temperature variability is closely linked to the forcings, while decadal circulation variability has a large random component which leads to considerable spread of regional temperatures or precipitation among different simulations (Wagner and Zorita, 2004; Yoshimori et al., 2005; Raible et al., 2005). In particular the Northern and Southern Annular Modes (NAM/SAM) have been shown in modelling studies to be caused by internal atmospheric processes (Limpasuvan and Hartmann, 1999) and empirical NAM and SAM reconstructions have also shown considerable variability that is apparently not linked to forcings (Cook et al., 2002; Jones and Widmann, 2004; Fogt and Bromwich, 2006; Jones et al., 2009). Secondly, there is ample evidence for a forced component of decadal and longer scale circulation variability (e.g., Hartmann et al., 2000; Shindell et al., 2001; Thompson and Solomon, 2002; Zorita et al., 2004; Arblaster and Meehl, 2006; Stendel et al., 2006; Fogt et al., 2009), but it is difficult to simulate due to the complexity of processes involved, which include for instance stratospheric dynamics and chemistry. A comparison of observed and simulated Northern Hemisphere, large-scale winter circulation trends for the period 1955-2005 showed for instance that none of the currently used GCMs is able to simulate the observed trends, which are likely to be a combination of a response to the forcings and of random variability (Gillett, 2005). Until forced circulation variabilty can be successfully simulated, it may partly be taken into account in paleoclimate simulations through assimilation of empirical circulation estimates.

The methods described in this section control the largescale atmospheric circulation variability in simulations such that it is close to prescribed target patterns. In principle it might be possible to indirectly control the circulation through assimilating temperature patterns, but so far this has not been tested. In the examples discussed here the target anomaly patterns are constant and the goal is to simulate the average conditions during a certain period and to test hypotheses about processes that caused past temperature anomalies. However, the methods are also designed to specifiy timedependent anomalies in transient simulations, but this has not yet been done. The assimilated large-scale circulation anomalies are either hypothetical situations or are based on a statistical upscaling of available early instrumental and proxy data.

This general approach has first been suggested by von Storch et al. (2000). The Pattern Nudging (PN) approach presented in Sect. 3.3.2 follows directly the Data Assimilation Through Upscaling and Nudging (DATUN) idea outlined in von Storch et al. (2000), whereas the Forcing Singular Vector (FSV) method presented in Sect. 3.3.1 uses a different method to control the atmospheric circulation in the model. In both cases an artificial forcing $f$ is added to the model tendencies to keep the simulated states close to the target patterns, but the two methods differ in the construction of the artificial forcing terms. If differences between simulated and target states originate from an incomplete or incorrect representation of the response to forcings, the forcing term can be interpreted as a crude way to account for the missing processes in the model equations. If the differences are due to non-predictable chaotic variability, they are the means by which the simulated states are kept close to reality.

Statistical upscaling models have been used extensively in palaeoclimatology to link proxy data for the last millenium or long instrumental records from multiple sites to the intensities of hemispheric- or continental-scale temperature (Mann et al., 1998, 2008) or circulation patterns (Cook et al., 2002; Luterbacher et al., 2002; Jones and Widmann, 2003; Jones et al., 2009). They are based on statistical relationships between the local data and large-scale climate variability obtained from spatially (almost) complete fields which are available for large parts of the 20th century. These relationships are then applied to the past to infer large-scale climate variability from the local data. Compared to the use of local data in the assimilation framework outlined in Sects. 2 and 3.2 the obvious advantage and original reason for these methods is that large-scale climate information can be obtained without running climate models and without dealing with the theoretical and technical challenges of assimilation. The FSV and PN methods are designed to use this existing large-scale information in simulations directly and at relatively low computational costs.

The statistical link is usually formulated via linear methods, such as Multiple Linear Regression, Principal Component Regression, pattern-based regression methods (e.g. Canonical Correlation Analysis), or via Regularised Expectation Maximation. The key assumption on which the upscaling approach relies is the stability of the statistical 
relationships over time, which however can not be fully tested with empirical data. Moreover there are questions related to how details of the statistical methods affect the reconstructions, which have mainly been discussed with respect to temperature reconstructions (von Storch et al., 2004; Rutherford et al., 2004; Bürger et al., 2006; Lee et al., 2008; Christiansen et al., 2009), but which in principle also apply to circulation variables. In addition upscaling assumes the invertability of the relationship between the large-scale state and the local information (which is closely linked to the observation operator), in other words it assumes that two different large-scale states lead to different local observations. Although these issues need to be taken seriously and may be seen as suggesting that DA based on upscaling is less preferable than DA based on forward modelling of local information, it should be noted that in the context of palaeoclimatology the question arises how stable over time a given forward operator is, and how the choice of forward operators affects the DA results. Thus similar methodological challenges are present in both cases, yet avoiding the invertability problem is a clear principle advantage of forward modelling.

\subsubsection{Forcing singular vectors}

This section describes a technique that determines small perturbations to the time evolution of the prognostic variables of the model (the tendencies) that lead the atmospheric model to a pre-defined target pattern. In terms of Eq. (1), a model forcing perturbation $f$ is added to the model $\mathrm{F}$ on the righthand side of this equation. These tendency perturbations are determined to result in large perturbation growth during a short period of time (of several days length). The tendency perturbations $f$ are referred to as forcing singular vectors (Barkmeijer et al., 2003). In the examples discussed here the method is used to assimilate only one large-scale circulation pattern, although multiple patterns are possible. Applications to patterns of variability in physical aspects of the atmosphere (like temperature) or ocean dynamics are theoretically possible, but put demanding requirements on the model used.

If $\boldsymbol{\Psi}_{T}$ denotes the proxy-based reconstruction of atmospheric circulation and $\boldsymbol{\Psi}_{M}$ the circulation in the model, then these fields can be expressed as

$$
\begin{aligned}
& \boldsymbol{\Psi}_{T}(\boldsymbol{x}, t)=\overline{\boldsymbol{\Psi}}_{T}(\boldsymbol{x})+\alpha_{T}(t) \boldsymbol{\Phi}_{T}(\boldsymbol{x}) \\
& \boldsymbol{\Psi}_{M}(\boldsymbol{x}, t)=\overline{\boldsymbol{\Psi}}_{M}(\boldsymbol{x})+\alpha_{M}(t) \boldsymbol{\Phi}_{T}(\boldsymbol{x})+\sum_{i} \alpha_{i}(t) \boldsymbol{\Phi}_{i}(\boldsymbol{x}),
\end{aligned}
$$

where $\overline{\boldsymbol{\Psi}}_{T}$ is a (modern) climatology and $\overline{\boldsymbol{\Psi}}_{M}$ the model's equivalent. The two climatologies need not to be similar, and when using intermediate complexity models, usually are not. The pattern $\boldsymbol{\Phi}_{T}$ is referred to as the target pattern and its time dependency is captured in the target time expansion coefficient $\alpha_{T}$. The set of patterns $\boldsymbol{\Phi}_{i}(\boldsymbol{x})$ can be any basis of the state space orthogonal to $\boldsymbol{\Phi}_{T}$. There is no fundamental reason for separating the time dependence and the spatial pattern as is done here, it is merely convenient for the applications where only the amplitude of the target pattern $\boldsymbol{\Phi}_{T}(\boldsymbol{x})$ is time-dependent. This is the case in three out of the four FSV examples discussed below, while in one example a target pattern is assimilated that has both temporal and spatial variability on a year-to-year timescale. In this case, the term $\alpha_{T}(t) \boldsymbol{\Phi}_{T}(\boldsymbol{x})$ needs to be written in the more general from $\boldsymbol{\Phi}_{T}(\boldsymbol{x}, t)$ and the remainder of this section can easily be generalised to include this case as well.

The aim is to bring, in a time-averaged sense, the coefficient $\alpha_{M}$ close to the target value $\alpha_{T}$, while the expansion coefficients $\alpha_{i}(t)$ can assume any values. The tendency perturbations $f$ are constructed to produce after some optimisation time a deflection of the model atmospheric state in the direction of the target pattern $\boldsymbol{\Phi}_{T}$. The amplitude of this deflection is aimed at reducing the difference between the target value $\alpha_{T}$ and the projection coefficient $\alpha_{M}$. If the target value has a time dependency, it will usually vary on timescales far larger than the typical time step of the model, which is a consequence of the fact that large spatial scales are associated with long timescales. The optimisation time will be on the order of days, which is much larger than the model time step and much smaller than the typical timescale of the target coefficient.

If the tendency perturbations are sufficiently small, the evolution of deviations of the model atmospheric state that results from tendency perturbations can be computed by a linearisation of the dynamical model along a (timedependent) solution of this model. Thus the linear evolution of a perturbation $\varepsilon$, measuring the deviation between a control and perturbed model run, satisfies

$$
\frac{\mathrm{d} \varepsilon}{\mathrm{dt}}=\mathbf{L} \varepsilon+\boldsymbol{f},
$$

where $\mathbf{L}$ is the time-dependent linearisation of the model along a solution. For a forcing perturbation $f$, the vector $\varepsilon(t=T) \equiv \mathcal{M} f$ is simply determined by integrating Eq. (6) to time $t=T$ with initial condition $\varepsilon(t=0)=0$. The forcing perturbation is now determined by minimisation of

$$
\left|\mathbf{P}\left(\mathcal{M} \boldsymbol{f}-\left(\alpha_{T}-\alpha_{M}\right) \boldsymbol{\Phi}_{T}\right)\right|
$$

where $\boldsymbol{\Phi}_{\boldsymbol{T}}$ is the target pattern and $\mathbf{P}$ is a projection operator. Through the use of the latter only information over the spatial domain that is available in the reconstruction enters the cost function. A fast minimisation routine requires the derivative of Eq. (7) with respect to $f$, which can be efficiently computed using the adjoint of $\mathcal{M}$. The requirements of having a linearisation of the climate model, or a part of the climate model, and an adjoint of this linearisation makes the FSV approach not applicable to every model. Although numerical methods exist that automatically generate the code of the adjoint model from the model code (Giering and Kaminski, 1998; Heimbach et al., 2005) not many atmosphere GCMs 


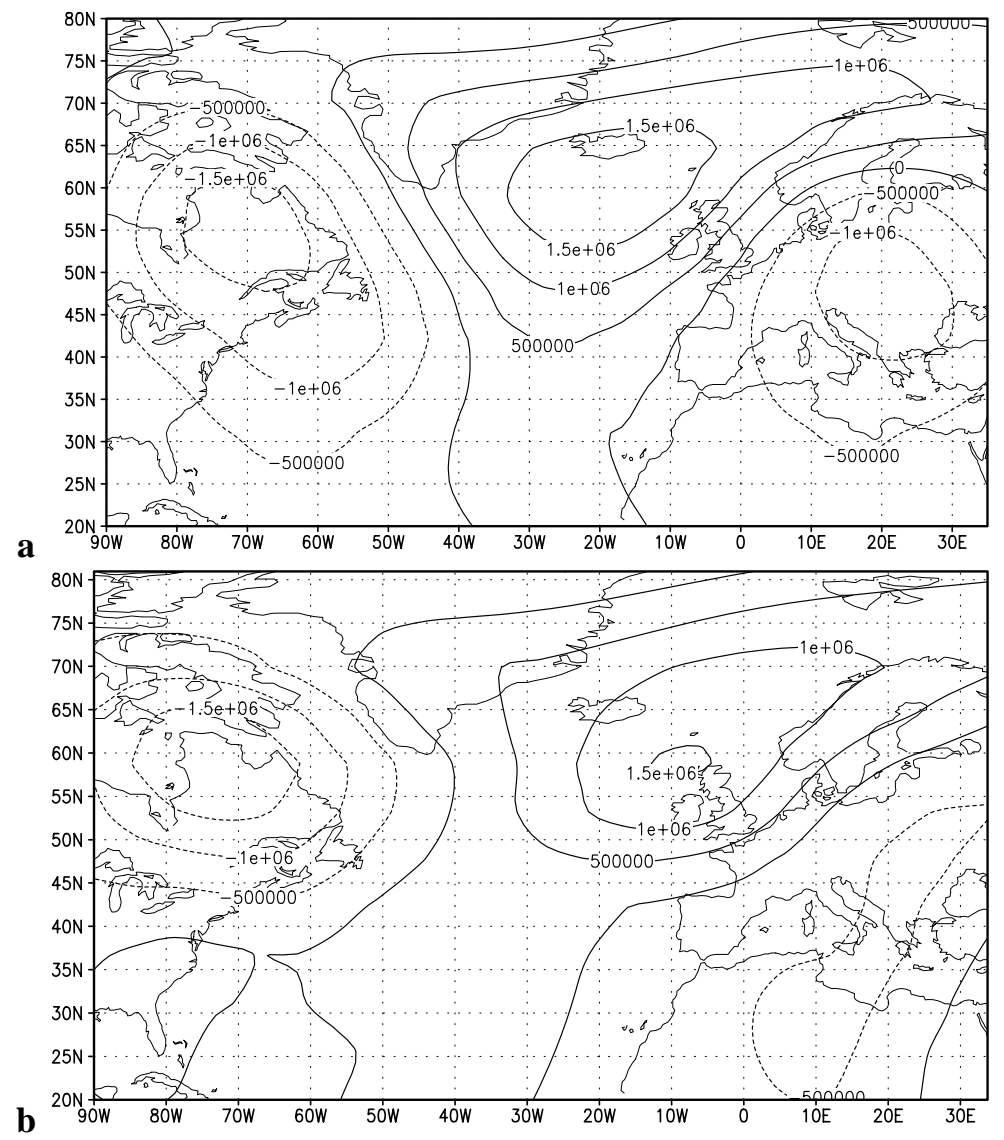

Fig. 3. Stream function anomaly $\Psi\left(\mathrm{m}^{2} \mathrm{~s}^{-1}\right)$ : (a) target pattern in the data assimilation, and (b) mean difference in winter (DJF) between the data assimilated run and the control run.

have this feature. An extensive and more technical discussion of this approach can be found in Barkmeijer et al. (2003) and van der Schrier and Barkmeijer (2005).

This method has been used in several palaeoclimatic studies (van der Schrier and Barkmeijer, 2005, 2007; van der Schrier et al., 2007; Luterbacher et al., 2010; Palastanga et al., 2010). To illustrate the method, we show results using the intermediate complexity model ECBilt-Clio. A linearisation of the dynamic core of the atmospheric part (ECBilt) of the climate model and its adjoint exist. They have been used earlier in predictability studies, e.g. Barkmeijer et al. (1993). The effect of parameterised processes is not included in the computation of $\boldsymbol{f}$; an accurate approximation if the optimisation time $T$ is sufficiently small.

One application (van der Schrier and Barkmeijer, 2005) assimilated the averaged atmospheric circulation over the North Atlantic sector for the 1790-1820 period, sometimes referred to as the Dalton Minimum, and one of the cold spells in the Little Ice Age. Figure 3 shows the target pattern $\boldsymbol{\Phi}_{\boldsymbol{T}}$, in terms of the $800 \mathrm{hPa}$ stream function anomaly, for the winter season. Stream function is a mathematical expression that describes the pattern of a two-dimensional flow. Lines in the horizontal plane where the stream function is constant give the direction of the flow. The target pattern is assimilated only in winter in the model, the model evolves freely in the remaining seasons. The lower panel shows the winter stream function anomaly at the $800 \mathrm{hPa}$ level, averaged over the length of the simulation and relative to the control climatology $\overline{\boldsymbol{\Psi}}_{M}$. There is a distinct qualitative similarity between the two patterns, with a reproduction of the tripole of the target pattern. The FSV approach successfully assimilates the information contained in the target pattern with repect to the strength and position of the negative and positive anomalies over Labrador and Iceland, whereas the negative anomaly over the European continent is not reproduced.

The simulation shows very large changes in $2 \mathrm{~m}$ temperatures over the European continent compared to the control simulation (Fig. 4a and b). In the winter (DJF) season, temperatures are more than $3^{\circ} \mathrm{C}$ colder over northern Scandinavia to around $0.5^{\circ} \mathrm{C}$ colder over Spain. In the summer (JJA) season, temperatures are lower in the eastern half of the North Atlantic ocean with minima of circa $-0.9^{\circ} \mathrm{C}$ over the 

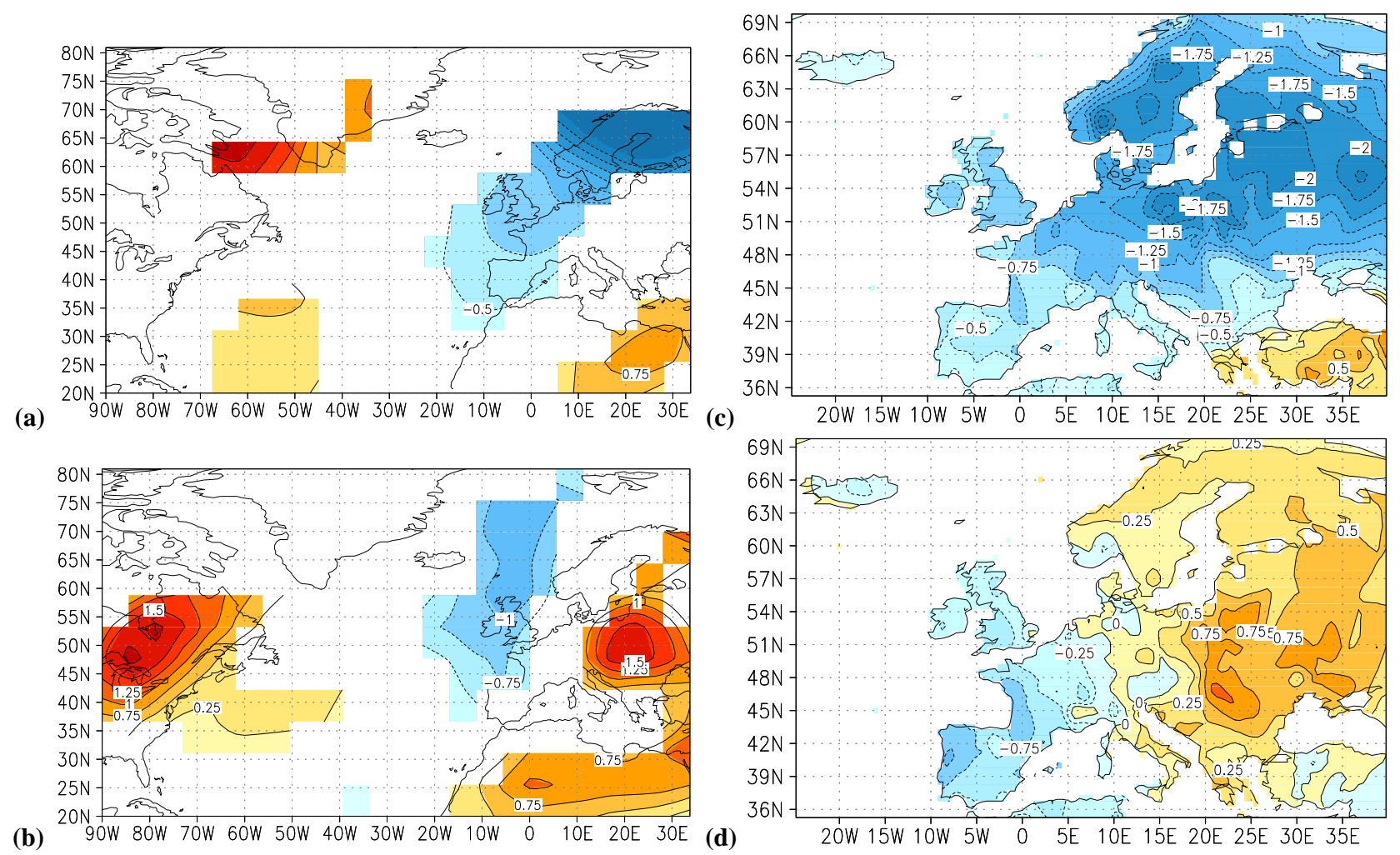

Fig. 4. Left-hand panels: difference in $2 \mathrm{~m}$ temperature $(K)$ between the data assimilated and the control run, averaged over 25 years, (a) winter (DJF) and (b) summer (JJA). All temperature changes shown are statistically significant at the 5\% level. Right-hand panels: difference in reconstructed surface air temperature $(K)$ for the period 1790-1820 AD with respect to 1971-2000, (c) winter (DJF), and (d) summer (JJA). Reconstructed temperatures are from Luterbacher et al. (2004).

UK. Positive anomalies are found over Poland and western Russia. Reconstructed temperatures for this period (Luterbacher et al., 2004) show a compelling similarity with the simulated temperatures (Fig. $4 \mathrm{c}$ and d) for both the winter and summer season. In van der Schrier and Barkmeijer (2005) it is shown that the winter temperature response is related to the anomalous atmospheric circulation, whereas the summer response is related to a feedback via ocean and soil-moisture dynamics. This illustrates the strength of the DA, where different climatic components are coupled and the simulated climate remains dynamically consistent with the assimilated data. We note however that we do not exclude an additional direct effect of the solar and volcanic radiative forcing, in particular on larger spatial scales, and that the circulation anomaly itself could be a response to the forcings.

A problem associated with the FSV methodology is stumbled upon by van der Schrier and Barkmeijer (2007). In that study, positive and negative phases of the Pacific-North American (PNA) pattern were assimilated. None of the dominant natural modes of variability of the ECBilt-Clio model bears a direct similarity with the PNA pattern, but the first few natural modes of variability have a nonzero projection on the PNA.
This results in an over-amplification of parts of the PNApattern, while other parts of the PNA-pattern are suppressed. In order to reach a time-averaged atmospheric circulation with persistent negative or positive PNA conditions, it was required to artificially enhance or weaken the monopoles of the target pattern in order to counteract the model's tendency to distort the PNA pattern. This problem seems to be associated with unrealistic aspects of the model rather than with a conceptual problem in the DA approach. Data assimilation with the FSV method has not been tested with a model more complex than ECBilt-Clio.

The drawback associated with the model deficiency described above puts some limitations to the applicability of this method for DA. In Luterbacher et al. (2010), a sea-level pressure (SLP) pattern is discussed which is constant for the JFM season, but has a year-to-year variability. This sea-level pressure pattern is assimilated into the ECBilt-Clio model to produce a climate that is dynamically consistent with the reconstructed atmospheric circulation. The SLP pattern is first related to stream function, which is the prognostic variable of the ECBilt model, and then the yearly varying pattern is assimilated in the ECBilt-Clio model using the FSV technique. For each year, the JFM-averaged stream function is 


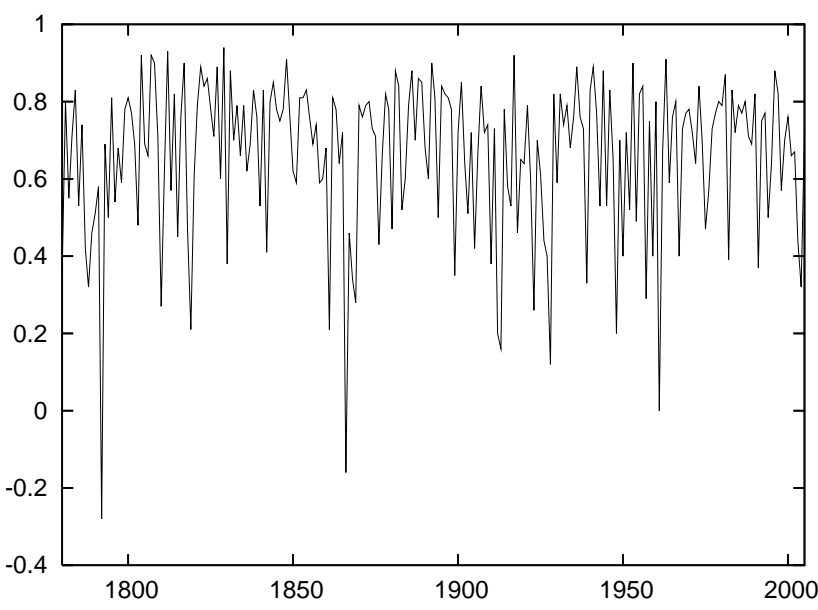

Fig. 5. Pattern correlations between fields of the simulated stream function at the $800 \mathrm{hPa}$ level, averaged over JFMA, and the reconstruction of stream function as derived from a SLP reconstruction.
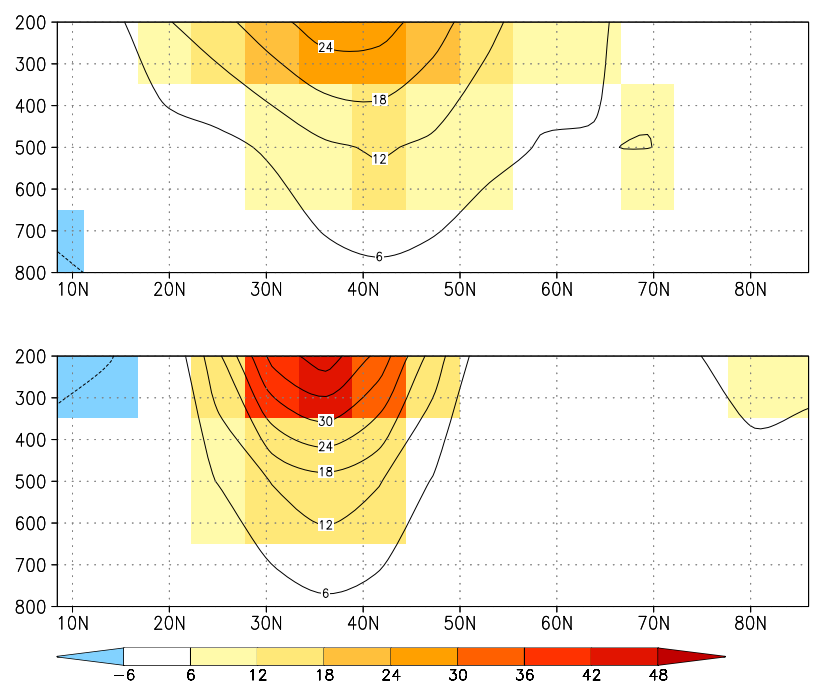

Fig. 6. Zonally averaged zonal velocity $\left(\mathrm{m} \mathrm{s}^{-1}\right)$ for the control simulation (upper panel), and the data assimilated experiment (lower panel). The zonal velocity is averaged over the North Atlantic sector $\left(60^{\circ} \mathrm{W}, 40^{\circ} \mathrm{E}\right)$ and averaged over the December-February period. Both contours and colourbar denote zonally averaged zonal velocity.

determined as deviation from the mean of the control climate, and compared to the target pattern. The pattern correlation coefficients are shown in Fig. 5, which shows that for many years the pattern correlation is reasonably high, but the pattern correlation drops to near-zero (or below zero) values for some years. The lack of a resemblance between the target pattern and the model's natural modes of variability are related to the poor performance in these years.
Finally, the FSV as well as PN approach discussed in the next section, can be used for experiments where hypothetical atmospheric circulations are assimilated. One example is given by van der Schrier et al. (2007), where tendency perturbations are calculated that nearly double the strength of the North Atlantic subtropical jet. These tendency perturbations were calculated and applied on the $200 \mathrm{hPa}$ level of the model only. The study aimed to test an alternative hypothesis (Seager and Battisti, 2007) for rapid climate change involving strong variations in the North Atlantic subtropical jet that trigger a reorganisation of the atmospheric circulation in the North Atlantic sector and a cessation of the northward atmospheric heat transport. Figure 6 shows the zonally averaged zonal velocity over the North Atlantic sector for the DJF season, for the control simulation and one of two experiments. Next to the increase in the strength of the subtropical jet, the disappearance of the eddy-driven jet at mid-latitudes is observed in the assimilated experiment. The disappearance of the eddy-driven jet has dynamical origins in which a double jet situation is replaced with a single jet as the subtropical jet increases in strength. The latter study indicates that DA methods as discussed in this study may also prove useful for studies into atmospheric dynamics.

\subsubsection{Pattern nudging}

The aim of PN is very similar as in the FSV approach, namely to bring the model time expansion coefficient $\alpha_{M}(t)$ of a target pattern in Eq. (5) close to a target coefficient $\alpha_{T}(t)$. Analogously to the FSV approach the method is designed such that the time expansion coefficients $\alpha_{i}(t)$, which are related to the other patterns, are not affected, in other words $\mathrm{PN}$ aims at simulated states that have a specified projection onto the target pattern rather than being identical to the target pattern. The motivation is the fact that large-scale circulation indices such at the NAM and SAM indices describe such a projection rather than represent the full spatial field. The difference to the FSV approach is how the simulation is controlled. Pattern nudging does not use knowledge about the dynamical evolution of a perturbation, and is based on the expectation that if a perturbation is introduced the circulation anomalies will change in the direction of this perturbation. The approach taken is a simple Newtonian relaxation in which the additional forcing term $\boldsymbol{f}$, which is called nudging term, is proportional to the difference between the simulated and the target state in the one-dimensional subspace defined by the target pattern. The nudging term is thus given by

$\boldsymbol{f}=G\left(\alpha_{T}(t)-\alpha_{M}(t)\right) \boldsymbol{\Phi}_{T}$,

where $G$ is a constant that determines the strength of the nudging and has the dimension $1 /$ time. The simulated field $\Psi_{\text {mod,old }}(\boldsymbol{x}, t)$ is modified by the nudging to

$\boldsymbol{\Psi}_{\text {mod,new }}(\boldsymbol{x}, t)=\boldsymbol{\Psi}_{\text {mod,old }}(\boldsymbol{x}, t)+2 \Delta t \boldsymbol{f}$, 
where $\Delta t$ is the time step of the model. A generalization to nudging with respect to multiple, mutually orthogonal target patterns is straightforward.

This simple nudging approach has the advantage that it does neither require linearisations of the dynamical model nor adjoint models and can thus be implemented without very large technical effort, which makes it suitable for GCMs. PN is implemented in the ECHAM4 atmosphere GCM and has been used with a T30 horizontal resolution (approx. 3.75 lat $\times 3.75$ lon or $400 \mathrm{~km} \mathrm{lat} \times 400 \mathrm{~km}$ lon) and 19 hybrid sigma-pressure levels with the highest at $10 \mathrm{hPa}$. The ECHAM4 model with a finer T42 resolution is described in Roeckner et al. (1996), and Stendel and Roeckner (1998) showed that it still performs well with the lower T30 resolution, which is computationally less expensive and thus particularly suited for long simulations in palaeoclimatology. The T30 version of ECHAM4 has been coupled to the HOPE-G ocean model by Legutke and Voss (1999) and this so-called ECHO-G model has been used for a 1000 year long equilibrium simulation with present day forcing conditions, which has been described and validated in Min et al. (2005a,b), as well as for transient simulations for the last 500 years and the last 1000 years (von Storch et al., 2004; Zorita et al., 2004; Fischer-Bruns et al., 2005; González-Rouco et al., 2006). The experiments discussed here have been conducted with the uncoupled ECHAM4 and climatological sea surface temperatures, in order to analyse the atmospheric response to $\mathrm{PN}$ without ocean feedbacks and to save computing time during the test phase. Experiments with the coupled model are in preparation.

In applications it is likely that the target pattern and coefficient describe circulation patterns such as the NAM or SAM, and are thus based on SLP fields. However, PN is not directly applied to SLP (or surface pressure, which is the equivalent prognostic variable in ECHAM), because all circulationrelated variables above the surface would still be free, and internally generated variability could potentially make it difficult to keep the atmosphere close to the target state. In addition particular care would be needed to ensure conservation of mass if the surface pressure was nudged. Therefore the nudging is used in the lower and middle troposhere and is applied to the horizontal vorticity of the wind field. The wind field in the free, extratropical atmosphere is approximately geostrophic and divergence-free, and thus well defined by vorticity. The vorticity target patterns are the linear signals of the SLP target time expansion coefficient.

This approach works generally well in test experiments in which the model is nudged towards positive and negative states of the NAM. The exception is the summer season, where it appears that the smaller spatial structures of the target pattern do not allow geostrophic adjustment. In the other seasons the simulated SLP anomalies are close but not identical to the target patterns. Discrepancies may partly be explicable by the non-constrained orthogonal components, but it also seems that the model tends to respond to the nudging with anomalies that are close to its internal variability patterns, for instance with a NAM pattern that has similarities to EOF1 of SLP in ECHAM. In this respect PN behaves similar to FSV, which, as discussed above, is problematic if the target patterns are very different from the model's own dominant variability patterns. The nudging constant $G$ can be chosen such that the simulation is close to the target index, but still retains considerable variability of the target pattern time expansion coefficient on daily timescales. A key property of PN is that aspects of circulation variability that are different from the target pattern, for instance synoptic-scale variability, evolve freely, but are consistent with the nudged state of the target pattern.

Here we present an experiment in which the atmospheric circulation has been nudged towards a negative NAM index of one (monthly) standard deviation. This simulation represents a target circulation anomaly similar to the one used for the FSV simulations discussed in the previous section. As the current version of PN has only been developed and tested with respect to nudging the NAM pattern, and as the first transient simulations will be based on specifying the NAM index, the NAM pattern rather than the full reconstructed SLP anomaly during the Dalton Minimum has been used as a target pattern. Figure 7 shows the winter NAM pattern (for a positive index of one standard deviation) and the SLP winter (DJF) anomaly in a 20 year long nudged simulation relative to a non-nudged simulation. The target pattern and the response have a clearly similar spatial structure and the amplitudes of the local response anomalies are consistent with the prescribed negative NAM index. Differences in the structure between target and response pattern can indicate the limitations of PN, but can also be due to sampling effects and to the fact that PN only prescribes the amplitude of the target pattern and does not constrain the amplitudes of all orthogonal patterns.

The response pattern is similar to the reconstructed Dalton Minimum anomaly (Fig. 3a) as it shows positive pressure anomalies over Iceland and Northern Europe, and negative anomalies over Southern Europe, the northwest Atlantic and northeastern America. Over western Europe both patterns indicate anomalous flow from northeasterly or easterly directions. However, the exact locations of maxima and minima, and the directions of the geostrophic flow are different. Over the North Pole this seems clearly a consequence of the hemispheric PN target pattern, whereas the locations of the two simulated negative anomalies in the Atlantic sector and the strong Pacific anomaly are features that are not part of the NAM target pattern and that appear to be a model-specific response to the NAM forcing.

The simulated temperature anomaly (Fig. 8) is very similar to the well-known NAM temperature signal (Thompson and Wallace, 1998) and is consistent with anomalous advection of air masses according the circulation anomaly. It shows lower than normal temperatures over Western and Northern Europe and higher temperatures over Turkey and the Black 

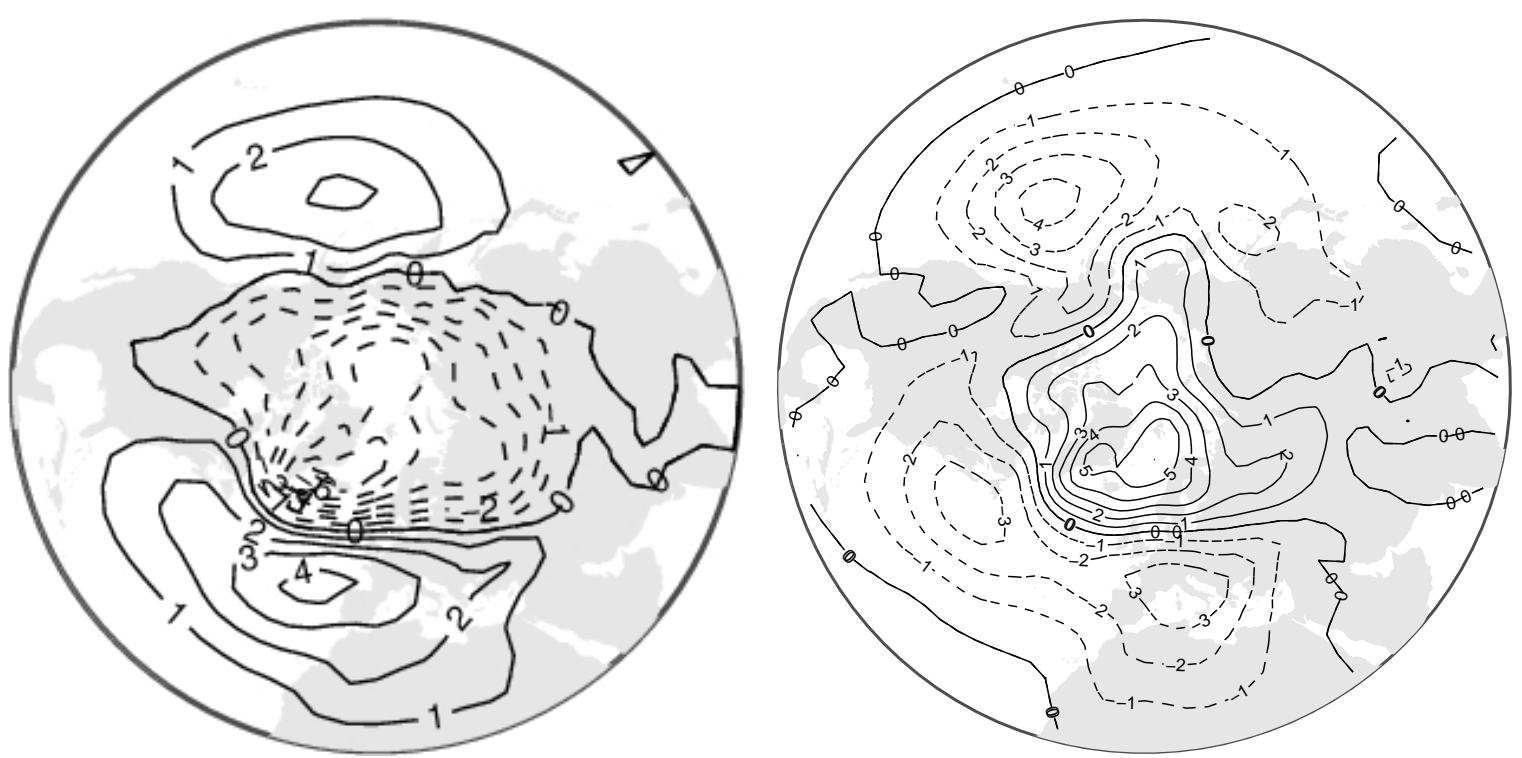

Fig. 7. Left: winter SLP anomaly for a positive NAM index of one standard deviation (hPa). Right: mean winter (DJF) SLP difference $(\mathrm{hPa})$ between a 20 year long simulation with ECHAM4 nudged towards a negative NAM index of one standard deviation and a 20 year long control simulation.

Sea region. Compared to the temperature reconstruction in Fig. 4 there is agreement over Western and Northern Europe and over Turkey, whereas Eastern Europe has strong negative anomalies in the reconstruction and small negative to positive anomalies in the simulation. The simulated positive temperature anomalies are consistent with the advection of warm air from Northern Africa into Eastern Europe and the Black Sea region according to the simulated circulation anomaly, which in this aspect is not in agreement with the reconstructed anomaly (Fig. 3a).

PN has also been implemented in the HadCM3 model and a simulation nudged towards a negative winter NAO index, which aims at representing the circulation during the Maunder Minimum, is discussed in Palastanga et al. (2010). This experiment is idealised to the point that radiation changes, due to changes in volcanic dust loading or solar activity, are ignored. The Palastanga et al. (2010) study aims to assess whether a persistently negative NAO-type circulation could be the primary driver of climate change as seen in the Maunder Minimum period. The resulting temperature anomaly has a similar structure to the one obtained with the ECHAM4 model, but the cold anomaly over Europe is shifted eastward, with the consequence that simulated temperatures are still lower than normal over Northern Europe, but close to average over western and central Europe, whereas temperature reconstructions during this period show negative anomalies over all of Europe. The partly unrealistic simulated temperature anomaly is tentatively attributed by Palastanga et al. (2010) to a too strong mean westerly flow in HadCM3.

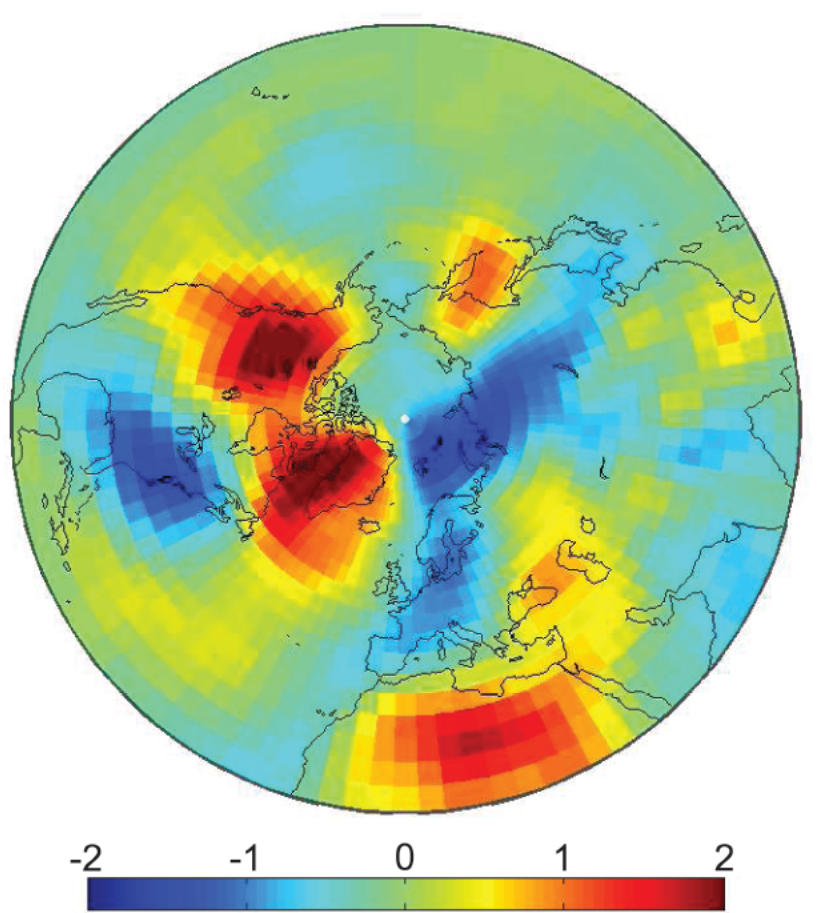

Fig. 8. Mean winter (DJF) 2 m temperature difference $(K)$ between a 20 year long simulation with ECHAM4 nudged towards a negative NAM index of one standard deviation and a 20 year long control simulation. 


\section{Summary and conclusions}

The temporal evolution of quasi-random internal climate variability on decadal timescales can not be simulated in climate models, and complex climate responses to external forcings are difficult to simulate. Details of internal variability in simulations and climate reconstructions can only be brought in agreement through DA, and in cases where forcing signals are unrealistically simulated DA may also be useful. Although DA has the potential to improve estimates of past climate variability for regions in which proxy data are available, the main added value compared to purely statistical climate reconstructions is that it yields spatially complete fields in a dynamically consistent way. Simulations with DA provide information for variables and at locations for which no proxy data are available, and thus allow the analysis of dynamical processes that caused the local climate variability at the locations covered by proxy data.

Here we have presented three methods for performing DA in the context of palaeoclimatology, namely selection of ensemble members, Forcing Singular Vectors, and Pattern Nudging. The first two methods are implemented using EMICs, while the third method is implemented in GCMs. All methods have been successful in bringing the simulations closer to reconstructions. However, as could be expected, DA has a tendency to produce anomalies that are within the model's range of internal variability for a given external forcing. For the ensemble method this is the case by construction, but with the FSV and PN methods it is also difficult to assimilate target patterns that are different from internal variability patterns. Moreover, the PN simulations with HadCM3 show that biases in the mean simulated climate can affect the temperature response to circulation variability. This is also not surprising as the influence of the mean flow on links between circulation and temperature anomalies has been already discussed in Groll et al. (2005) and Groll and Widmann (2006). Thus the different methods are associated with similar methodological challenges. It should be noted that problems linked to an unrealistic simulation of the mean climate and of the statistical properties of climate variability can be expected to become less important as increasing computing power allows to use higher resolution and more sophisticated models for DA in palaeoclimatology. An advantage of the ensemble member selection is that in principle it uses forward modelling to link the simulations and the proxies and thus avoids the potential non-invertability problem associated with the upscaling that is used in the FSV and PN approach. However, current implementations still use very simple forward models.

Despite these issues all DA simulations presented here were consistent with empirical knowlege over large parts of Europe. These simulations demonstrate the value that DA adds compared to statistical reconstructions of individual variables by providing physically consistent and spatially complete information for a large number of variables, which can aid process understanding. In particular it has has been shown that the cold periods in Europe around 1680-1720 and around $1790-1820$ can be produced by anomalous atmospheric circulation that is associated with a negative NAO or NAM index and northerly or easterly wind anomalies. It has also been shown that the cold period around 1790-1820 is associated with colder eastern Atlantic SSTs which help to maintain cold conditions all year long over Northern Europe.

DA also provides a framework to test the compatibility between proxies and models. In order to satisfy its constitutive equations a model may not be able to simultaneously follow all the constraints given by a set of proxy data. Proxies that are not in good agreement with the simulation have then to be carefully analysed in order to determine the reason for the discrepancies, which could for instance be related to model biases, or instationarities and misinterpretation of the proxies. FSV and PN are much simpler than the filter or variational methods used in numerical weather prediction, while the selection of ensemble members is conceptually related to filters. A major obstacle for applying variational methods in palaeoclimatology is that the current implementations in weather prediction use adjoint models, which are based on linear approximations for the climate dynamics. On the timescales given by the temporal resolution of proxy data (e.g. interannual) the standard linear approximations are not valid. We note however that FSV is able to use adjoints by prescribing reconstructed climate anomalies related to long timescales periodically at intervals of several days, which means that the linear approximation of the climate dynamics can still be used between the intervals. Some high-frequency temporal variability of the amplitude of the target pattern is maintained by choosing sufficiently long intervals. Similarly PN prescribes target values at every model time step and maintains high-frequency variability through a sufficiently small nudging constant. We thus do not exlude that modifications of the methods used in weather prediction could be used in palaeoclimatology.

The methods currently used in palaeoclimatology are not formulated within the standard DA framework and would therefore not be able to provide estimates for the uncertainty of the DA results even if the uncertainties of models and proxy data were known, which however usually is not the case. The potential of DA to provide uncertainties that are lower and better defined than those of statistical climate reconstructions is not yet explored and further progress towards exploiting this advantage of DA can be expected. It would require not only further development of DA methods but also of forward models for proxy data that provide error estimates.

Acknowledgements. This paper is a result of the workshop on Holocene climate variability over Scandinavia, hosted by the Bert Bolin Centre for Climate Research, Stockholm University, in April 2008, and of the workshop on data assimilation to study the climate of the past millennium hosted by the Université catholique de Louvain in May 2007. The authors thank H. von Storch, 
I. Kirchner, O. Talagrand, C. Wunsch, J. M. Jones, D. Grawe, and J. Annan for valuable contributions and comments, as well as E. Zorita and an anonymous reviewer for very constructive reviews. M. Widmann was partly funded for this work through DEKLIM (Deutsches Klimaforschungsprogramm) by the German Federal Ministry of Education and Research. Hugues Goosse is research associate with the Fonds National de la Recherche Scientifique (FRNS-Belgium).

Edited by: Q. Zhang

\section{References}

Annan, J. D., Hargreaves, J. C., Edwards, N. R., and Marsh, R.: Parameter estimation in an intermediate complexity Earth system model using and Ensemble Kalman Filter, Ocean modelling, 8, 135-154, 2005.

Arblaster, J. M. and Meehl, G. A.: Contributions of external forcing to Southern Annular Mode Trends, J. Climate, 19, 3896-2905, 2006.

Barkmeijer, J., Houtekamer, P., and Wang, X.: Validation of a skill prediction model, Tellus, 45A, 424-434, 1993.

Barkmeijer, J., Iversen, T., and Palmer, T. N.: Forcing singular vectors and other sensitive model structures, Q. J. Roy. Meteor. Soc., 129, 2401-2423, doi:10.1256/qj.02.126, 2003.

Braconnot, P., Otto-Bliesner, B., Harrison, S., Joussaume, S., Peterchmitt, J.-Y., Abe-Ouchi, A., Crucifix, M., Driesschaert, E., Fichefet, Th., Hewitt, C. D., Kageyama, M., Kitoh, A., Laîné, A., Loutre, M.-F., Marti, O., Merkel, U., Ramstein, G., Valdes, P., Weber, S. L., Yu, Y., and Zhao, Y.: Results of PMIP2 coupled simulations of the Mid-Holocene and Last Glacial Maximum Part 1: experiments and large-scale features, Clim. Past, 3, 261277, doi:10.5194/cp-3-261-2007, 2007.

Brohan, P., Kennedy, J. J., Harris, I., Tett, S. F. B., and Jones, P. D.: Uncertainty estimates in regional and global observed temperature changes: A new data set from 1850, J. Geophys. Res, 111, D12106, doi:10.1029/2005JD006548, 2006.

Brovkin, V., Levis, S., Loutre, M. F., Crucifix, M., Claussen, M., Ganopolski, A., Kubatzki, C., and Petruokov, V.: Stability analysis of the climate-vegetation system in the northern high latitudes, Climatic Change, 57, 119-138, 2003.

Bürger, G., Fast, I., and Cubasch, U.: Climate reconstruction by regression - 32 variations on a theme, Tellus Series A, 58, 227235, 2006

Burgers, G., van Leeuwen, P., and Evensen, G.: Analysis scheme in the ensemble Kalman Filter, Mon. Weather Rev., 126, 17191724, 1998.

Cappe, O., Godsill, S., and Moulines, E.: An overview of existing methods and recent advances in sequential Monte Carlo, in: Proceeding of IEEE, 95, 899-924, 2007.

Christiansen, B., Schmith, T., and Thejll, P.: A surrogate ensemble study of climate reconstruction methods: stochasticity and robustness. J. Climate, 22, 951-976, 2009.

Claussen, M., Mysak, L. A., Weaver, A. J., Crucifix, M., Fichefet, T., Loutre, M. F., Weber, S. L., Alcamo, J., Alexeev, V. A., Berger, A., Calov, R., Ganopolski, A., Goosse, H., Lohmann, G., Lunkeit, F., Mohkov, I. I., Petoukhov, V., Stone, P., and Wang, Z.: Earth System Models of Intermediate Complexity: closing the gap in the spectrum of climate system models, Clim. Dynam., 18, 579-586, 2002.

Collins, M.: Quantitative use of paleo-proxy data in global circulation models, Geophysical Research Abstracts, 5, 0114, 2003.

Compo, G. P., Whitaker, J. S., and Sardeshmukh, P. D.: Feasibility of a 100 reanalysis using only surface pressure data, Bull. American Meteor. Soc., 86, 175-190, 2006.

Compo, G. P., Whitaker, J. S., Sardeshmukh, P. D., and Matsui et al., N.: The Twentieth Century Reanalysis Project, Quaterly J. Roy. Meteor. Soc, submitted, 2010.

Cook, E. R., D’Arrigo, R. D., and Mann, M. E.: A well-verified, multiproxy reconstruction of the winter North Atlantic Oscillation index since AD 1400, J. Clim., 15, 1754-1764, 2002.

Crespin, E., Goosse, H., Fichefet, T., and Mann, M. E.: The 15th century Arctic warming in coupled model simulations with data assimilation, Clim. Past, 5, 389-401, doi:10.5194/cp-5-3892009, 2009.

Crucifix, M., Loutre, M. F., Tulkens, P., Fichefet, T., and Berger, A.: Climate evolution during the Holocene: a study with an Earth system model of intermediate complexity, Clim. Dynam., 19, 43-60, 2002.

Delworth, T. L. and Mann, M. E.: Observed and Simulated Multidecadal Variability in the Northern Hemisphere, Clim. Dynam., 16, 661-676, 2000.

Evans, M. N., Reichert, B. K., Kaplan, A., Anchukaitis, K. J., Vaganov, E. A., Hughes, M. K., and Cane, M. A.: A forward modelling approach to paleoclimatic interpretation of tree-ring data, J. Geophys. Res.-Biosciences, 111, G03008, doi:10.1029/2006JG000166, 2006.

Evensen, G.: Advanced data assimilation for strongly nonlinear dynamics, Mon. Weather Rev., 125, 1342-1353, 1997.

Evensen, G.: The Ensemble Kalman Filter: theoretical formulation and practical implementation, Ocean Dynam., 53, 343-367, 2003.

Fischer-Bruns, I., von Storch, H., González-Rouco, J. F., and Zorita, E.: Modelling the variability of midlatitude storm activity on decadal to century time scales, Clim. Dynam., 25, 461-476, 2005.

Fogt, R., Jones, J. M., Marshall, G., Jones, P., and Visbeck, M.: Historical SAM variability. Part II: simulations of the SAM, J. Climate, 20, 5346-5365, 2009.

Fogt, R. L. and Bromwich, D. H.: Decadal variability of the ENSO teleconnection to the high-latitude South Pacific governed by coupling with the Southern Annular Mode, J. Climate, 19, 979997, 2006.

Gillett, N.: Climate modelling - Northern Hemisphere circulation, Nature, 437, p 496, 2005.

Giering, R., and Kaminski, T.: Recipies for Adjoint Code Construction, ACM Trans. Math. Software, 24, 437-474, 1998

González-Rouco, J. F., Beltrami, H., Zorita, E., and von Storch, H.: Simulation and inversion of borehole temperature profiles in surrogate climates: Spatial distribution and surface coupling, Geophys. Res. Lett., 33, L01703, doi:10.1029/2005GL024693, 2006.

Goosse H., Selten, F. M., Haarsma, R. J., and Opsteegh, J. D.: A mechanism of decadal variability of the sea-ice volume in the Northern Hemisphere, Clim. Dynam., 19, 61-83, 2002.

Goosse, H., Renssen, H., Timmermann, A., Bradley, R., and Mann, M.: Using paleoclimate proxy-data to select optimal realisations 
in an ensemble of simulations of the climate of the past millennium, Clim. Dynam., 27, 165-184, 2006.

Goosse, H., Lefebvre, W., de Montety, A., Crespin, E., and Orsi, A.: Consistent past half-century trends in the atmosphere, the sea ice and the ocean at high southern latitudes, Clim. Dynam., 2009.

Goosse, H., Crespin, E., de Montety, A., Mann, M. E., Renssen, H., and Timmermann, A.: Reconstructing surface temperature changes over the past 600 years using climate model simulations with data assimilation, J. Geophys. Res.-Atmos., 115, D09108, doi:10.1029/2009JD012737, 2010.

Groll, N. and Widmann, M.: Sensitivity of temperature teleconnections to orbital changes in AO-GCM simulations, Geophys. Res. Lett., 13, L12705, doi:10.1029/2005GL025578, 2006.

Groll, N., Widmann, M., Jones, J. M., Kaspar, F., and Lorenz, S.: Simulated relationships between regional temperatures and large-scale circulation during the early Eemian interglacial (125 kyr BP) and the pre-industrial period, J. Climate, 18, 40324045, 2005.

Hartmann, D., Wallace, J.M., Limpasuvan, V., Thompson, D., and Holton, J.: Can Ozone depletion and global warming interact to produce rapid climate change?, Proc. National Academy of Science, 97, 1412-1417, 2000.

Hawkins, E. and Sutton, R.: Potential predictability of rapid changes in the Atlantic meridional overturning circulation, Geophys. Res. Lett., 35, L11603, doi:10.1029/2008GL034059, 2008.

Heimbach, P., Hill, C., and Giering, R.: An efficient exact adjoint of the parallel MIT general circulation model, generated automatically via automatic differentiation, Future Gener. Comp. Sy., 21, 1356-1371, 2005.

Hurrell, J. W.: Decadal trends in the North-Atlantic Oscillation regional temperatures and precipitation, Science, 269, 676-679, 1995.

Jansen, E., Overpeck, J., Briffa, K. R., Duplessy, J.-J., Joos, F., Masson-Delmotte, V., Olago, D., Otto-Bliesner, B., Peltier, W. R., Rahmstorf, S., Ramesh, R., Raynaud, D., Rind, D., Solomina, O., Villalba, R., and Zhang, D.: Palaeoclimate, In: Climate Change 2007 - The Physical Science Basis. Contribution of WG1 to the Fourth Assessment Report of the IPCC, 2007.

Jones, J. M. and Widmann, M.: Instrument- and tree-ring-based estimates for the Antarctic Oscillation, J. Climate, 16, 3511-3524, 2003.

Jones, J. M. and Widmann, M.: Atmospheric science - Early peak in Antarctic Oscillation Index, Nature, 432, 290-191, 2004.

Jones, J. M., Fogt, R., Widmann, Marshall, G., Jones, P., and Visbeck, M.: Historical SAM variability. Part I: Century lenghth seasonal reconstructions of the SAM, J. Clim., 22, 5319-5345, 2009.

Kalnay, E., Kanamitsu, M., Kistler, R., Collins, W., Deaven, D., Gandin, L., Iredell, M., Saha, S., White, G., Woollen, J., Zhu, Y., Chelliah, M., Ebisuzaki, W., Higgins, W., Janowiak, J., Mo, K. C., Ropelewski, C., Wang, J., Leetmaa, A., Reynolds, R., Jenne, R., and Joseph, D.: The NCEP/NCAR reanalysis project, Bull. American Meteor. Soc., 77, 437-471, 1996.

Kistler, R., Kalnay, E., Collins, W., Saha, S., White, G., Woollen, J., Chelliah, M., Ebisuzaki, W., Kanamitsu, M., Kousky, V., van den Dool H., H., Jenne, R., and Fiorino, M.: The NCEP/NCAR 50year reanalysis: Monthly means CD-ROM and documentation, Bull. American Meteor. Soc., 82, 247-267, 2001.

Knight, J.R, Allan, R.J., Folland, C.K., Vellinga, M., and Mann,
M.E.: A signature of persistent natural thermohaline circulation cycles in observed climate, Geophys. Res. Lett., 32, L20708, doi:10.1029/2005GL024233, 2005.

Lee, T. C. K., Zwiers, F. W., and Tsao, M.: Evaluation of proxybased millennial reconstruction methods, Clim. Dynam., 31, 263-281, 2008.

Legutke, S. and Voss, R.: The Hamburg atmosphere-ocean coupled model ECHO-G, Tech. Rep. 18, German Climate Computing Center (DKRZ), 1999.

Limpasuvan, V. and Hartmann, D. L.: Eddies and the annular modes of climate variability, Geophys. Res. Lett., 26, 3133-3136, 1999.

Liu, J. and West, M.: Sequential Monte Carlo Methods in practice, chap. Combined parameter and state estimation in simulationbased filtering, Springer, 2001.

Lorenz, S. and Lohmann, G.: Acceleration technique for Milankovitch type forcing in a coupled atmosphere-ocean general circulation model: method and application for the Holocene, Clim. Dynam., 23, 727-747, 2004.

Luterbacher, J., Xoplaki, E., Dietrich, D., Rickli, R., Jacobeit, J., Beck, C., Gyalistras, D., Schmutz, C., and Wanner, H.: Reconstruction of sea level pressure fields over the Eastern North Atlantic and Europe back to 1500, Clim. Dynam., 18, 545-561, 2002.

Luterbacher, J., Dietrich, D., Xoplaki, E., Grosjean, M., and Wanner, H.: European seasonal and annual temperature variability, trends and extremes since 1500, Science, 303, 1499-1503, 2004.

Luterbacher, J., König, S. J., Franke, J., van der Schrier, G., et al.: Circulation dynamics and influence on European and Mediterranean January-April climate over the past half millennium: Results and insights from instrumental data, documentary proxy evidence and coupled climate models, Climatic Change, 101, 201234, 2010.

Mann, M. E., Bradley, R. S., and Hughes, M. K.: Global-scale temperature patterns and climate forcing over the past six centuries, Nature, 392, 779-787, 1998.

Mann, M. E., Zhang, Z., Hughes, M. K., Bradley, R. S., Miller, S. K., Rutherford, S., and Ni, F.: Proxy-based reconstructions of hemispheric and global surface temperature variations over the past two millennia, Proc. Nat. Acad. Sci., 105, 13252-12257, 2008.

Min, S., Legutke, S., Hense, A., and Kwon, W.: Internal variability in a 1000 -yr control simulation with the coupled climate model ECHO-G - I. Near-surface temperature, precipitation and mean sea level pressure, Tellus Series A, 57, 605-621, 2005 a.

Min, S., Legutke, S., Hense, A., and Kwon, W.: Internal variability in a 1000 -yr control simulation with the coupled climate model ECHO-G - II. El Nino Southern Oscillation and North Atlantic Oscillation, Tellus Series A, 57, 622-640, 2005b.

Moberg, A., Alexandersson, H., Bergstroem, H., and Jones, P. D.: Were Southern Swedish summer temperatures before 1860 as warm as measured?, Int. J. Climatol., 23, 1495-1521, 2003.

Palastanga, V., van der Schrier, G., Weber, S. L., Kleinen, T., Briffa, K. R., and Osborn, T.: Atmosphere and ocean dynamics: contributors to the European Little Ice Age?, Clim. Dynam., in press, doi:10.1007/s00382-010-0751-0, 2010.

Pitt, M. and Shepard, N.: Filtering via simulation: auxiliary particle filter, J. American Statistical Association, 94, 590-599, 1999.

Raible, C. C., Stocker, T. F., Yoshimore, M., Renold, M., Beyerle, 
U., Casty, C., and Luterbacher, J.: Northern hemispheric trends of pressure indices and atmospheric circulation patterns in observations, reconstructions, and coupled GCM simulations, J. Climate, 18, 3968-3982, 2005.

Reichert, B. K., Bengtsson, L., and Akesson, O.: A statistical modellig approach for the simulation of local paleoclimatic proxy records using general circulation model output, J. Geophys. Res., 104, 19071-19083, 1999.

Reichert, B. K., Bengtsson, L., and Oerlemans, J.: Midlatitude forcing mechanisms for glacier mass balance investigated using general circulation models, J. Climate, 14, 3767-3784, 2001.

Renssen, H., Goosse, H., Fichefet, T., Brovkin, V., Driesschaert, E., and Wolk, F.: Climate evolution during the Holocene: a study with an Earth system model of intermediate complexity, Clim. Dynam., 24, 23-43, 2005.

Roeckner, E., Arpe, K., Bengtsson, L., Christoph, M., Claussen, M., Dümenil, L., Esch, M., Giorgetta, M., Schlese, U., and Schulzweida, U.: The atmospheric general circulation model ECHAM4: model description and simulation of present-day climate, Tech. Rep. 218, Max Planck Institut for Meteorology, 1996.

Rutherford, S., Mann, M. E., Osborn, T. J., Bradley, R. S., Briffa, K. R., Hughes, M. K., and Jones, P. D.: Proxy-based northern hemisphere surface temperature reconstructions: Sensitivity to method, predictor network, target season, and target domain, J. Clim., 18, 2308-2329, 2004.

Seager, R. and Battisti, D. S.: Challenges to our understanding of the general circulation: abrupt climate change, in: The Global Circulation of the Atmosphere: Phenomena, Theory, Challenges, edited by: Schneider, T. and Sobel, A. S., Princeton University Press, 331-371, 2007.

Selten, F.M., Haarsma, R. J., and Opsteegh, J.D.: On the mechanism of North Atlantic decadal variability, J. Clim., 12, 1956-1973, 1999.

Shindell, D. T., Schmidt, G. A., Mann, M. E., Rind, D., and Waple, A.: Solar Forcing of Regional Climate Change During the Maunder Minimum, Science, 294, 2149-2152, 2001.

Stendel, M. and Roeckner, E.: Impacts of horizontal resolution on simulated climate statistics in ECHAM4, MPI report, Max Planck Institute for Meteorology, 1998.

Stendel, M., Mogensen, I. A., and Christenden, J. H.: Influence of various forcings on global climate in historical times using a coupled atmosphere-ocean general circulation model, Clim. Dynam., 26, 1-15, 2006.

Sutton, R. T. and Hodson, D. L. R.: Atlantic ocean forcing of North American and European summer climate, Science, 309, 115118,2005

Swinbank, R., Shutyaev, V., and Lahoz, W. A., eds.: Data Assimilation for the Earth System, vol. IV. Earth and Environmental Sciences - 26, Kluwer Academic Publishers, 2003.

Tett, S. F. B., Betts, R., Crowley, T. J., Gregory, J., Johns, T. C., Jones, A., Osborn, T. J., Ostrom, E., Roberts, D. L., and Woodage, M. J.: The impact of natural and anthropogenic forcings on climate and hydrology since 1500, Clim. Dynam., 28, 3-34, 2007.

Thompson, D. W. J. and Solomon, S.: Interpretation of recent Southern Hemisphere climate change, Science, 296, 895-899, 2002.
Thompson, D. W. J. and Wallace, J. M.: Regional climate impacts of the Northern Hemisphere Annular Mode, Science, 293, 8589,2001

Thompson, D. W. J. and Wallace, J. M.: Annular Modes in the extratropical circulation. Part 1: Month-to-month variability, J. Climate, 13, 1000-1016, 2000.

Thompson, D. W. J. and Wallace, J. M.: The Arctic Oscillation signature in wintertime geopotential height and temperature, Geophys. Res. Lett., 25, 1297-1300, 1998.

Uppala, S. M., Källberg, P. W., Simmons, A. J., and Adrae, U.: The ERA-40 reanalysis., Q. J. Roy. Meteor. Soc., 131, 2961-3012, 2005.

van der Schrier, G. and Barkmeijer, J.: Bjerknes' hypothesis on the coldness during 1790-1820 AD revisited, Clim. Dynam., 24, 355-371, doi:10.1007/s00382-004-0506-x; Erratum: Clim. Dynam. doi:10.1007/s00382-005-0053-0, 2005.

van der Schrier, G. and Barkmeijer, J.: North American 18181824 drought and 1825-1840 pluvial and their possible relation to the atmospheric circulation, J. Geophys. Res.-Atmospheres, 112, D13102, doi:10.1029/2007JD008429, 2007.

van der Schrier, G., Drijfhout, S. S., Hazeleger, W., and Noulin, L.: Increasing the Atlantic subtropical jet cools the circum-North Atlantic region, Meteorol. Z., 16, 675-684, 2007.

von Storch, H., Cubasch, U., González-Rouco, J., Jones, J., Voss, R., Widmann, M., and Zorita, E.: Combining paleoclimatic evidence and GCMs by means of Data Assimilation Through Upscaling and Nudging, pp. 28-31, Proc. 11th Symposium on Global Climate Change Studies, AMS Long Beach, CA, 2000.

von Storch, H., Zorita, E., J. M. Jones, Y. D., and S. F. B. Tett, .: Reconstructing past climate from noisy data, Science, 306, 679682, 2004.

Wagner, S. and Zorita, E.: The influence of volcanic, solar and CO2 forcing on the temperatures in the Dalton Minimum (17901830): a model study, Clim. Dynam., 25, 205-218, 2004.

Wagner, S., Widmann, M., Jones, J., Haberzettl, T., Lücke, A., Mayr, C., Ohlendorf, C., Schäbitz, F., and Zolitschka, B.: Transient simulations, empirical reconstructions and forcing mechanisms for the Mid-Holocene hydrological climate in Southern Patagonia, Clim. Dynam., 29, 333-355, 2007.

Wang, Y. M., Mysak, L., Wang, Z., and Brovkin, V.: The greening of the McGill Paleoclimate model. Part II: simulation of Holocene millennial-scale climate changes, Clim. Dynam., 24, 481-496, 2005.

Wanner, H., Beer, J., Bütikofer, J., Crowley, T., Cubasch, U., Flückiger, J., Goosse, H., Grosjean, M., Joos, F., Kaplan, J. O., Küttel, M., Müller, S., Prentice, C., Solomina, O., Stocker, T., Tarasov, P., Wagner, M., and Widmann, M.: Mid to late Holocene climate change - an overviev, Q. Sci. Rev., 27, 1791-1828, 2008.

Weber, S. L. and Oerlemans, J.: Holocene glacier variability: three case studies using an intermediate-complexity climate model, Holocene, 13, 353-363, 2003.

Weber, S. L., Crowley, T. J., and van der Schrier, G.: Solar irradiance forcing of cenntennial climate variability during the Holocene, Clim. Dynam., 22, 539-553, 2004.

Whitaker, J. S., Compo, G. P., Wei, X., and Hamill, T. M.: Reanalysis without radiosondes using ensemble data assimilation, Mon. Weather Rev., 132, 1190-1200, 2004. 
Wunsch, C.: Discrete inverse state estimation problems, Cambridge University Press, 371 pp., 2006.

Yoshimori, M., Stocker, T., CC, C. R., and Renold, M.: Externally forced and internal variability in ensemble climate simulations of the Maunder Minimum, J. Climate, 18, 4253-4270, 2005.
Zorita, E., von Storch, H., González-Rouco, J., Cubasch, U., Luterbacher, J., Legutke, S., Fischer-Bruns, I., and Schlese, U.: Transient simulation of the climate of the last five centuries with an atmosphere-ocean coupled model: Late Maunder Minimum and the Little Ice Age, Meteorol. Z., 13, 271-289, 2004. 